\title{
Product recycling of automotive parts - trends and issues
}

Remanufacturing is a dynamically developing area of the automotive industry. It allows the original equipment manufactures to diversify their activities and sell manufacturer-warrantied subassemblies through a dealership network but at lower prices compared to new products. The paper presents the process of remanufacturing of automotive subassemblies and characterizes the benefits for the industry and vehicle end-users. Examples have been shown of the activities of vehicle manufacturers in the area of product recycling and development of remanufacturing technologies.

Key words: recycling, remanufacturing, automotive parts

\section{Introduction}

The automotive industry is one of the key sectors of economy in developed countries. The worldwide vehicle fleet counts over 1.2 billion vehicles, out of which almost 910 million are passenger vehicles [7]. Each year, nearly 70 million passenger vehicles and another 22 million lightduty trucks and heavy-duty trucks are manufactured. It is estimated that by 2035 the number of vehicles will double.

The production, sales and service maintenance of vehicles are factors of economic growth in the world. The input of the automotive industry in the worldwide economy amounts to almost 2 trillion euros [8], which means that if we compared it to the GDP of a country, the automotive industry would be the seventh economy worldwide. The automotive industry plays and important role in the global use of natural resources, emissions to the atmosphere, water and soil, let alone production of waste. Recycling plays a significant role in the reduction of this environmental impact.

The dependence of the automotive sector on raw materials and some noble metals may in the future become a limitation of its development thus the supply management is a strategic challenge for this sector. The automotive sector is, for example, the largest consumer of lead. Its uses $60 \%$ of the world's production of this metal. Aside from the problems related to the possible shortages in the supplies of some metals - whether rare or not - the growth of the global demand for raw materials inevitably leads to increased prices. The implementation of a principle of material reuse, whenever there exists such an opportunity, not only leads to material and energy savings, prevents generating waste but also brings economic benefits. Additionally, such a policy remains in line with the principles of circular economy being introduced in the EU member states.

Circular economy assumes limited generation of waste and environment pollution resulting from the consideration of the relevant needs already on the design stage of the goods. It distinguishes two types of components: biological, to be reentered to the biosphere and technical - designed in such a way as to enable its reuse without entering the biosphere. Such an approach remains in opposition to the traditional concept of economy based on linear model referred to as "take, make, dispose", in which each product has a limited period of operation. Circular economy puts more pressure on reuse, repair, renewal and recycling of materials.

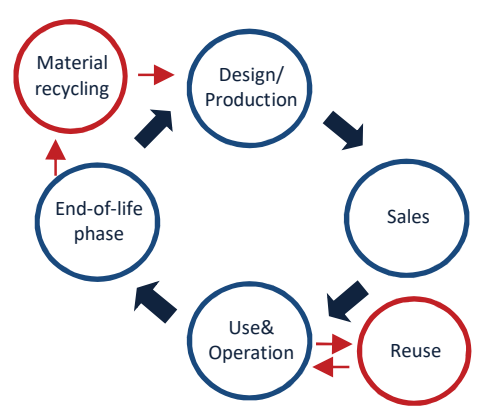

Fig. 1. Diagram of circular economy

Waste recycling may be carried out as product recycling or material recycling. Product recycling consists in restoring the technical parameters of parts or subassemblies so that they could be reused as spare parts in other vehicles in operation. These parts may come from on-going service maintenance or from end-of-life vehicles. Material recycling involves processing of waste to obtain secondary raw materials or other products used in the industry. As for endof-life vehicles, some disassembled parts (e.g. mirrors, bumpers) may be ready for refitting in other vehicles. Other parts disassembled during service procedures, must undergo remanufacturing. This is particularly the case for engines, engine aggregates, suspension systems, drivetrains. Remanufacturing is most often carried out on such components as fuel systems, hydraulic systems, cylinder heads, crankshafts, starter motors, alternators or transmissions.

The process of remanufacturing consists in restoring the original properties of end-of-life parts that are identical to the properties of a new product by a combination of such processes as disassembly, application of regenerative layers, renewal, repair and refitting. The said procedures result in the extension of the period of operation. Contrary to product recycling, remanufacturing requires direct manpower, development of appropriate technology and use of raw materials.

Remanufacturing is a dynamically developing area within the automotive industry. It allows the original equipment manufacturers to diversify their operations and provides them with a competitive tool in the fight with budget, aftermarket spare part suppliers. The value of the remanufactured automotive part market is to reach 130 billion euros by 2020 [5]. The greatest share in this market 


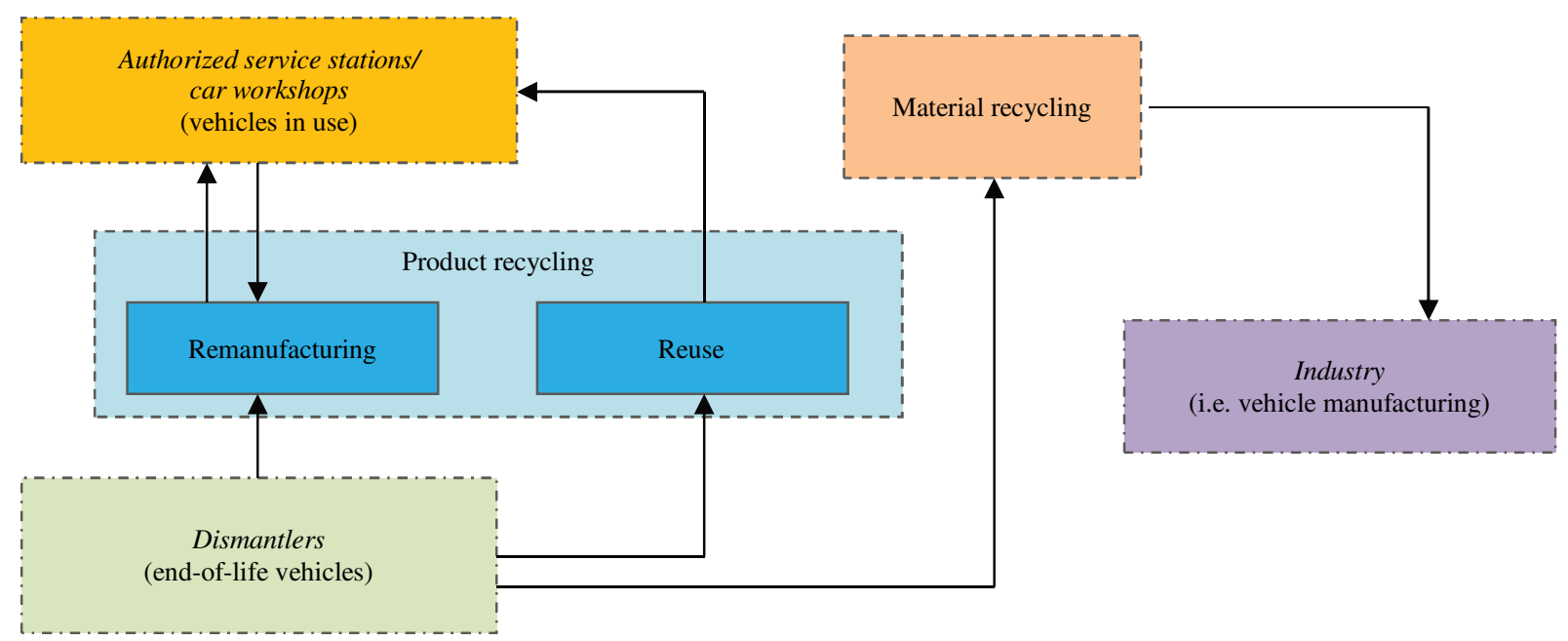

Fig. 2. Recycling flows in vehicle life cycle diagram

has the United States, while the most rapidly advancing market with the annual growth index of $25 \%$ is Asia. This sector employs 31 thousand people in the US and approx. 43 thousand people in Europe [6]. According to the estimations of European Association of Automotive Suppliers (CLEPA) and European Remanufacturing Network, the market of remanufactured parts in Europe is worth between 8 and 10 billion euros per annum [2, 4]. The entire European market of remanufacturing of the vehicles, machines and equipment is estimated at approx. 30 billion euros at a total employment level of 190 thousand people [4]. The greatest share have: aerospace $(42 \%)$, automotive $(25 \%)$, heavyduty and off-road (14\%) together constituting over $80 \%$ of the European remanufacturing market. Unfortunately, the relation between the revenues from remanufacturing to the revenues from the entire sector (sale of remanufactured and new parts) is still rather poor and amounts to $1.9 \%$. For the aerospace, subassembly remanufacturing already constitutes $11.5 \%$ of the market value but for the automotive sector this index is a mere $1.1 \%$.

Table 1. Remanufacturing market in Europe by sector [4]

\begin{tabular}{|l|c|c|c|c|}
\hline Sectors & $\begin{array}{c}\text { Turnover } \\
\text { (bn euro) }\end{array}$ & Firms & Employment & $\begin{array}{c}\text { Intensi- } \\
\text { ty }\end{array}$ \\
\hline Aerospace & 12.4 & 1000 & 71000 & $11.5 \%$ \\
\hline Automotive & 7.4 & 2363 & 43000 & $1.1 \%$ \\
\hline $\begin{array}{l}\text { Heavy duty and } \\
\text { off road }\end{array}$ & 4.2 & 581 & 31000 & $2.9 \%$ \\
\hline $\begin{array}{l}\text { Electronic \& } \\
\text { electrical equip. }\end{array}$ & 3.1 & 2502 & 28000 & $1.1 \%$ \\
\hline Furniture & 0.3 & 147 & 4000 & $0.4 \%$ \\
\hline Machinery & 1.0 & 513 & 6000 & $0.7 \%$ \\
\hline Marine & 0.1 & 1 & 1000 & $0.3 \%$ \\
\hline $\begin{array}{l}\text { Medical equip- } \\
\text { ment }\end{array}$ & 1.0 & 7 & 7000 & $2.8 \%$ \\
\hline Rail & 0.3 & 3 & 3000 & $1.1 \%$ \\
\hline Total & 29.8 & 7204 & 192000 & $1.9 \%$ \\
\hline
\end{tabular}

In the European market, the largest stakeholder is Germany with the share in total sales on the level of 2.4 billion euros. France, Spain and Great Britain with Ireland follow immediately with an approx. $10 \%$ share in the market. A slightly smaller share is held by Italy and the countries of Central and Eastern Europe.

\section{The advantages of product recycling}

Product recycling brings benefits to both the manufacturers and the vehicle end-users. For the manufacturers, the most crucial issue is the savings of the resources, hence the production costs.

In comparison to new parts, the production of regenerated parts saves [3]:

- $80 \%$ of energy,

- $88 \%$ volume of water,

- $92 \%$ mass of chemical products,

- $70 \%$ mass of waste.

The durability of the components after remanufacturing should not significantly differ from that of new parts and should at least reach $80 \%$ of their durability. However, vehicle manufacturers performing the remanufacturing at their own facilities (factory remanufacturing), subject the remanufactured parts to the same quality tests applied to new parts and guarantee the same durability and functionality. Remanufactured parts are covered with the same manufacturer warranty as the new ones.

The costs of remanufacturing should not exceed those of new parts. Otherwise, the remanufactured parts would not generate demand and the entire process would be economically unjustified. The total costs of remanufacturing should not exceed $60 \%$ of the costs of manufacturing of a new part. Most often, the costs fall in the range from 40 to $60 \%$ of the costs of a new part [6]. The savings on the cost of production result from the avoidance of production processes such as casting or melting (energy and thus money saving). The energy savings during a remanufacturing may reach up to $85 \%$ of the energy necessary to manufacture a new part.

From the point of view of the end-user, the main advantage is the competitive price of the remanufactured items. The price of a remanufactured part is usually50-70\% of a new part depending on the required expense.

Remanufacturing requires qualified manpower. Compared to the production of new parts, this type of activity does not involve advanced automation. In combination with the savings on the processing costs, it results that this type of activity is conducted relatively close to the sources of waste, hence is not 'delocalized', thus contributing to creat- 
ing new employment opportunities and the development of local economy.

Selling remanufactured parts and subassemblies to customers as an alternative to new products is also a trading argument for workshops and authorized service centres. It allows a repair of older vehicles using spare parts whose durability corresponds to the durability of the repaired vehicle at an acceptable cost that corresponds to the vehicle residual value. This extends the life cycle of vehicles whose further operation would be economically unjustified if repaired with new parts (when the cost of repair exceeds the vehicle residual value). Besides, for parts whose production was seized, remanufacturing is the only way to obtain them.

There are many challenges for business entities dealing with remanufacturing. The most important ones are: the perception of remanufactured parts by the customers as parts of lower quality, irregular supply of used subassemblies, resistance of the manufacturers of the original equipment, no access to product information and possible limitations in the application of remanufactured parts in warranty-covered products. Vehicle manufacturers who conduct remanufacturing by themselves are somewhat privileged, as they can obtain the used parts from their network of authorized service workshops, which ensures more stable sales and facilitates the logistics. They also have full access to information regarding the product and their clients have more trust in them if the parts are covered with a vehicle manufacturer warranty. Even the original equipment manufacturers must allow for irregular supplies of certain subassemblies for remanufacturing and different quality of the product at the beginning of the process.

Table 2. Comparison of remanufacturing and manufacturing of parts

\begin{tabular}{|l|c|c|}
\hline Category & Remanufactured parts & New parts \\
\hline Production cost & Low & High \\
\hline Energy consumption & Low & High \\
\hline Price for user & Low & High \\
\hline Automation & Low & High \\
\hline Labour intensity & High & Low \\
\hline Quality & High & High \\
\hline $\begin{array}{l}\text { Material supplies for produc- } \\
\text { tion (timing and quantity) }\end{array}$ & Uncertain & Stable \\
\hline Perception by the customer & Bad & Good \\
\hline
\end{tabular}

\section{The process of remanufacturing}

The regeneration starts with a preliminary assessment if a product is fit for further use. This inspection is decisive of the profitability of the remanufacturing, quality of the remanufactured parts and, simply, whether the process will be performed or not. The subassemblies are disassembled and their individual components are degreased and cleaned. The next step is a detailed evaluation of the technical condition of each of the components. The most important stage is proper remanufacturing of the components that consists in restoring their original properties and applying regenerative layers (chroming, ironing etc.). Some components are renewed and some are repaired. During remanufacturing of engines, only the engine block, the crankshaft and the connecting rods undergo the process, while the cylinder head, the injection pump and the turbocharger are new. The subassembly is then refitted. The last stage is the testing of individual parts and the entire subassembly to make sure it complies with the specifications of the original equipment.

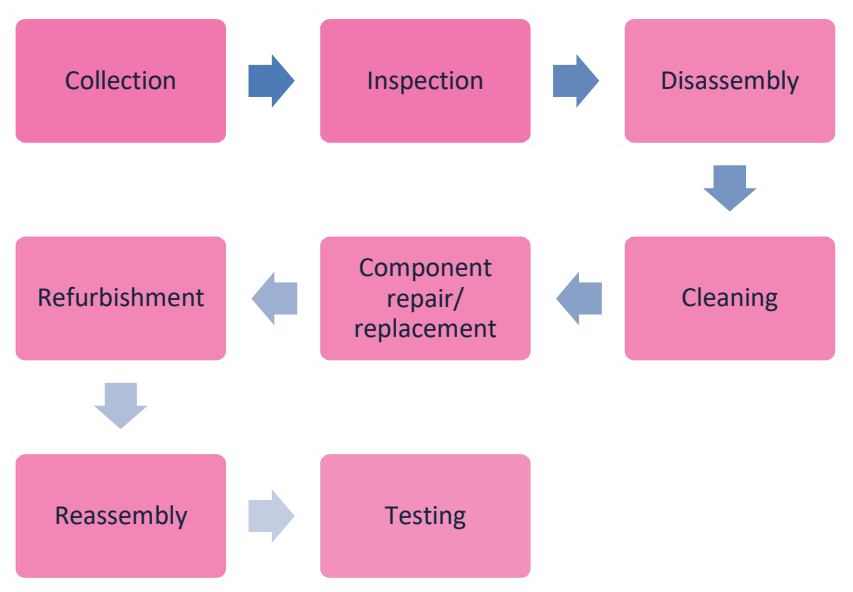

Fig. 3. Remanufacturing process

The disassembly is performed manually due to the versatility of the disassembled components and the necessity of selecting proper tools for the process. The longer the time of disassembly, the higher the cost of labor, which has a negative impact on the economic account. Parts that have been designed to allow for future disassembly (Design for Disassembly) reduce the costs of remanufacturing. In order to determine the optimum methods of disassembly, different solutions are applied such as the petri-net approach or the and/or graph serving the purpose of generating sequences of operations and hierarchical modular modelling.

Another process influencing the course of remanufacturing is cleaning of the parts. Currently commonly used methods are high temperature decomposition, shot blasting and high pressure water cleaning. A new alternative and, at the same time environment-friendly, method is supercritical carbon dioxide $\left(\mathrm{SC}-\mathrm{CO}_{2}\right)$ cleaning that is very useful in removing oil stains from the engine components and aluminium parts.

The key process during remanufacturing, however, is the restoration of the technical parameters and applying regenerative layers. One of the methods is honing (crosshatch). This is a technology of bore machining consisting in eliminating material surplus from the inner surface of a bore with abrasive stones. Other methods include surface processing based on laser metal alloy powder hardfacing that allows forming new layers and their quenching, which makes the layers more resistant to stress, ensures greater hardness and operational durability. One of the most recent methods is Plasma Transferred Wire Arc (PTWA) involving application of corrosion resistant material with the method of thermal plasma. The use of PTWA consists in applying a thin layer of material on the worn and porous components of an engine such as the cylinders. The corroded areas with material loss are filled and then polished and restored to the original dimensions.

The logistic chain related to remanufacturing of parts is a typical example of reverse logistics that includes all elements connected to the flow of products whose owner or user no longer wishes to use and forwards them back to the manufacturer distribution network or any other collectors 
[9]. Contrary to waste disposal, it focuses on such flows that aim at recovery of the product or waste through its repair or another form of reconditioning.

The logistic chain serving the purpose of collecting parts for remanufacturing and their distribution as spare parts includes selected links of a logistic chain of conventional distribution of new parts and those of the recycling networks of end-of-life vehicles. For parts disassembled in service operations, return shipments are used in modes of transport supplying new parts. Parts disassembled from vehicles for dismantling are forwarded to remanufacturing facilities via dedicated transport.

\section{Recycling of vehicle parts on selected examples}

A European leader among the automotive car manufacturers is Volkswagen AG. It started remanufacturing parts, including engines in 1947. The first products available after remanufacturing were cylinders, fuel pumps, carburettors, steering boxes and clutch pressure plates.

Ever since, the concern facilities have reconditioned approx. 7.7 million engines, 2.5 million transmissions and 68 million additional components [13]. Upon assessment, the disassembled engines and transmissions are subjected to remanufacturing at the Volkswagen works in Kassel or, if they are not good for product recycling, they are forwarded to material recycling. The basic activity of the Volkswagen works in Kassel is production of new manual and automatic transmissions (the facility supplies 4 million transmissions per annum for the entire VW group), exhaust systems and other subassemblies for the Passat, Polo and Golf models. Kassel also hosts a distribution centre of original parts. The combination of activities of part manufacturing and logistics facilitates a reduction of costs and capital expenditure related to remanufacturing of engines and transmissions.

In 2011 Volkswagen opened the first engine remanufacturing facility outside of Germany. The potential of the facility located in Dailan in East China is 15000 units per annum. $70 \%$ of the material mass is reused. Engines subjected to reconditioning are $50 \%$ cheaper compared to new engines and are sold under the brand Volkswagen Genuine Exchange Parts operating in the same scheme as Volkswagen Original Parts. The parts are remanufactured with an industrial method and are quality checked locally in the facility in terms of dimensions and operating parameters to ensure safety, technical standards and durability. Therefore, the manufacturer provides warranty identical to that issued for new parts.

The portfolio of parts and components available within the Volkswagen Passenger Cars brand's Genuine Exchange Parts is regularly extended. Currently the portfolio includes approx. 10 thousand items for passenger vehicles and light duty-trucks sold under the brands of Volkswagen and Audi. Thanks to the idea of part remanufacturing, Volkswagen guarantees supplies of spare parts for a minimum of 15 years from the moment of seizing serial production of a given model. The prices of these parts are, on average, lower by $40 \%$ compared to new parts. Remanufacturing of engines at the Volkswagen facilities allows saving approx. 7000 tons of steel [12]. The amount of steel contained in the regenerated engine to date would suffice to build 50 Eiffel Towers and 162 Golden Gate bridges[13].
The Renault company is another player having its facility specializing in part remanufacturing. The facility located in Choisy-le-Roi, France began its operations in 1949. It initially reconditioned combustion engines exclusively. In 1989, it extended its operations to injection pumps, then gearboxes (2003), injectors (2010) and turbocompressors (2013). The remanufactured parts are used only for repairs of vehicles already in operation. A customer can purchase a new or a remanufactured part at an authorized service workshop. The regenerated parts cover $70 \%$ of reference mechanical parts for $90 \%$ of the vehicle models manufactured under the brand of Renault. Collectively, Renault offers 19 product families mechanical, electronic, parts for the brake systems and air conditioning systems. Remanufactured parts are a proposal mainly targeting owners of vehicles older than 4 years. The prices are 50 to $70 \%$ of new parts.

Out of 120 used engines retrieved from end-of-life vehicles or damaged engines obtained from the service networks, on average, 100 remanufactured engines return to the market. The saving on the energy related to the delivery of the remanufactured engines reaches up to $70 \%$ compared to the production of new units.

Parts forwarded to the Choisy-le-Roi facility are sorted in the following way[3]:

- $43 \%$ of the part mass is reused in reconditioned subassemblies,

- $48 \%$ of the part mass is processed in foundries belonging to the group and is used for production of new parts,

- $\quad 9 \%$ of the remains is subject to other forms of recovery.

The facility does not generate any waste for disposal.

The Choisy-le-Roi facility employing 325 workers remanufactures spare parts of the market value of over100 million euros, which includes [3]:

- 14700 engines,

- 21200 transmissions,

- 32700 injection pumps,

- 151300 injectors,

- 3500 cylinder heads.

Toyota automaker also has a wide portfolio of remanufactured spare parts [10]. They are available at all European Toyota authorized services. The used parts coming from the dealer service networks are forwarded to the European distribution centre and then directly to the entities dealing with the process of remanufacturing .

Part remanufacturing has been performed in Toyota since 2001 when a business entity under the name of Ecoline Corporation was created responsible for the sales of used parts (including the remanufactured ones). In the European market, the reconditioned parts under the brand name of Toyota have been available since 2002 when remanufactured air-conditioning compressors and power assisted steering gears were introduced. A year later, the offer was extended by engines (with and without aggregates) and cylinder heads. Today, the following remanufactured subassemblies (tested and admitted for use by the Toyota standards) are available:

- engines,

- starter motors,

- alternators,

- complete clutch assemblies, 
- automatic transmissions,

- air-conditioning compressors,

- steering gears.

Each year Ecoline sells almost 50 used parts [11]. The sales of some remanufactured parts are much higher than the sales of new parts. Each year, service repairs rely on 3780 reconditioned transmissions (the sales of new transmissions are approx. 100 per annum) and the power assisted steering counts 10000 units per annum against 4700 new ones [11].

Ford uses a proprietary patented technology of Plasma Transferred Wire Arc developed at its research and innovation centre in Aachen, Germany. Ford has performed durability tests of the engines remanufactured with this method. The tests have confirmed the engine parameters, the durability and quality of the layer application after a mileage of $400000 \mathrm{~km}$ [1]. The warranty for reconditioned engines is the same as for the new ones. A downside of the PTWA process is the cost that is higher compared to the cost of remanufacturing with conventional methods. An advantage is the savings on the materials used in the reconditioning process and a reduction of the emission of $\mathrm{CO}_{2}$ by $50 \%$ compared to the production of new engines.

The market of subassembly remanufacturing has also been penetrated by Chinese companies. The possibilities of utilizing used parts are limited in China (due to a ban on use of parts retrieved from end-of-life vehicles), yet, the Chinese government has permitted a pilot activity in the area of vehicle part remanufacturing. In 2008 the first 14 companies were authorized and certified by the National
Development and Reform Commission and the further 28 in 2013 [14]. These companies mainly deal with the reconditioning of engines, transmissions, alternators, and steering gears. China remanufactures approx. 110 thousand engines, 60 thousand transmissions and a million of starter motors.

\section{Conclusions}

The supply of recycled materials and investing in recycling technologies have good prospects for the future. Product recycling in the form of part remanufacturing, however, is very often a more profitable solution in terms of reduction of waste negative impact on the environment, savings on energy and raw materials. Despite investments that require developing technologies and performing regenerations of engines and other subassemblies, this activity is also profitable for the vehicle manufacturers. It allows increasing the sales figures related to spare parts that are offered at reduced prices, retaining customers at authorized service networks (owners of older vehicles) and ensuring stability of spare part supplies at acceptable costs for those that are no longer manufactured.

Clients and vehicle users also put increasing pressure on part remanufacturing. In 2015, the US Senate passed a law (Federal Vehicle Repair Cost Savings Act) that imposes on Federal Agencies the necessity to use (if possible) remanufactured parts when maintaining fleets of vehicles. The total vehicle fleet of the Federal Government reaches 580 thousand vehicles and the annual expenses for vehicle maintenance reach 975 million US dollars [4].

\section{Bibliography}

[1] BOAGEY, R. Automotive Remanufacturing. Professional Engineering. 2017, 02, 31-32.

[2] CLEPA European Association of Automotive Suppliers, clepa.eu/what-we-do/publications/ (accessed 13.03. 2017).

[3] Ellen Mac Arthur Foundation. De l'économie circulaire appliquée a l'industrie automobile. www.ellenmacarthurfoundation. org/ fr/news/de-leconomie-circulaire-appliqueea-lindustrie-automobile-le-cas-pratique-de-lusine-de-choisyle-roi (accessed 15.03.2017).

[4] European Remanufacturing Network, Remanufacturing Market Study, European Commission, Brussels, 2015.

[5] Global Industry Analysis INC., The Global Automotive Parts Remanufacturing Market, www.strategyr.com/ MarketResearch/Automotive_Parts_Remanufacturing_Market_ Trends.asp (accessed 21.03.2017).

[6] LEE, C.-M., WOO, W.-S., YOUNG-HWA, R. Remanufacturing: Trends and Issues. International Journal of Precision Engineering and Manufacturing-Green Technology. 2017, 4(1), 113-125.

[7] Organisation Internationale des Constructeurs D'automobiles, Vehicles in use report, www.oica.net/category/vehicles-in-use/ (accessed 25.02.2017).

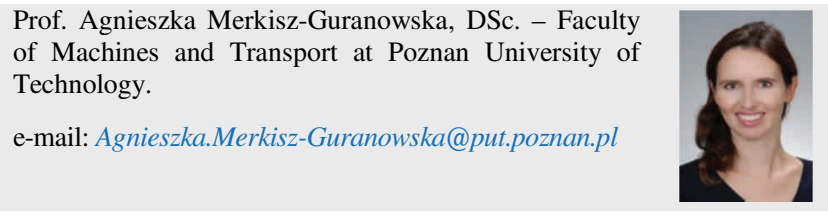

[8] Organisation Internationale des Constructeurs D'automobiles, Economic contributions, www.oica.net/category/economic-contributions/ (accessed 25.02.2017).

[9] STOCK, J.R. Development and implementation of reverse logistics programs. Council of Logistics Management, Oak Brook, USA, 1998.

[10] Toyota Motor Corporation. Recycling of cars, Europe. Toyota Motor Marketing Europe Environmental Affairs Office, Brussels, 2002.

[11] Toyota Motor Corporation. Vehicle recycling. Environmental Affairs Division Toyota Motor Corporation, 2014.

[12] Volkswagen Group. Group Management Report 2014, annualreport2014.volkswagenag.com/group-managementreport/sustainable-value-enhancement/environmentalmanagement/recycling.html (accessed 15.03.2017).

[13] Volkswagen Singapore, www.volkswagen.com.sg/en/service/genuine-parts-accessories/genuine-exchange-parts.html (accessed 18.03.2017).

[14] WEI, S., CHENG, D., SUNDIN, E., TANG, O. Motives and Barriers of the Remanufacturing Industry in China. Journal of Cleaner Production, 2015, 94, 340-351. 